https://doi.org/10.29296/25877305-2018-08-01

\section{Оптимизация ведения}

\section{детей с рекуррентными}

респираторными инсекциями

\section{в период сезонного}

\section{подъема заболеваемости}

В. Краснов, доктор медицинских наук, професссор

Приволжский исследовательский медицинский университет, Нижний Новгород

E-mail: dr.krasnov@mail.ru

Острые респираторные инсрекции - самая распространенная патология детского возраста, в подавляющем большинстве случаев имеющая вирусную этиологию. Отдельной проблемой являются дети с частыми повторными заболеваниями респираторного тракта, последнее чаще встречается у аллергиков и нередко сопровождается бактериальными осложнениями и обострениями хронических заболеваний. Комплексная профилактика рекуррентных респираторных инфрекций включает в себя коррекцию микробиоценоза, дотацию витаминов и минеральных веществ, а также применение препаратов интерферона интраназально.

Ключевые слова: педиатрия, дети, острые респираторные вирусные инфекции, рекуррентные респираторные инфекции, профилактика, интерферон, Гриппферон

Для цитирования: Краснов В. Оптимизация ведения детей с рекуррентными респираторными инсекциями в период сезонного подъема заболеваемости // Врач. - 2018; 29 (8): 3-7. https://doi.org/10.29296/258773052018-08-01
Если говорить непосредственно о работе врача в условиях поликлиники, то этиология респираторных инфекций остается нерасшифрованной в подавляющем большинстве случаев. В настоящее время известно около 200 (вероятно, еще больше) вирусов, поражающих дыхательные пути, в том числе относящихся к семейству Herpesviridae.

Разумеется, в детском возрасте имеют место заболевания респираторного тракта и различной бактериальной этиологии, чаще всего - пневмококковая инфекция. Основных возбудителей бактериальных ОРИ относительно немного - кроме пневмококка, это Haemophilus influenzae, Streptococcus pyogenes, Klebsiella pneumoniae, Moraxella catarrhalis, Staphylococcus aureus, Streptococcus viridans, Klebsiella ozaenae, Escherichia coli, грамотрицательные бактерии, такие как протей (Proteus) и синегнойная палочка (Pseudomonas aeruginosa).

Определенное место в этиологии данной группы заболеваний занимают микоплазмы и хламидии. Однако роль этих микроорганизмов в каждом конкретном случае должна быть аргументирована, поскольку, являясь оппортунистическими представителями микробной флоры, они достаточно широко распространены в популяции, и даже их наличие, определенное методом полимеразной цепной реакции, а тем более выявление антител класса $\mathrm{IgG}$, не являются абсолютным доказательством указанной этиологии данного случая поражения органов дыхания. Несмотря на многообразие бактериальных возбудителей, считают, что $\geq 95 \%$ заболеваний верхних дыхательных путей (ВДП) у дошкольников вызывают вирусы, и их значение в формировании данной патологии является определяющим. Врачу «первого контакта» (врач общей практики, педиатр общего профиля, семейный врач) крайне важно не переоценить возможную роль бактериальной флоры и воздержаться от назначения антибиотиков в тех случаях, когда в них нет необходимости.

Отдельная проблема, связанная с респираторной патологией, - повторные частые инфекционные заболевания органов дыхания, приходящиеся не только на холодное время года (особенно у детей раннего возраста, в большей степени - при начале посещения детского дошкольного учреждения). Эта проблема актуальна прежде всего для участкового педиатра, поскольку именно повторные респираторные инфекции составляют существенную часть общей заболеваемости в детском возрасте. Часто болеющими детьми (ЧБД) принято считать пациентов, которые чаще подвержены респираторным инфекциям, чем их сверстники, из-за транзиторных, корригируемых отклонений в защитных системах организма.

ЧБД - не нозологическая форма заболевания и не диагноз, а группа диспансерного наблюдения [1-3]. Ряд врачей применяют несколько расширенную аббревиатуру - ЧДБД (часто и длительно болеющие дети), поскольку именно у пациентов этой группы формирузавышенной для практического здравоохранения. 
ются различные, прежде всего, бактериальные осложнения, в конечном счете приводящие к затяжному инфекционному процессу. Следует заметить, что термин ЧДБД прост, понятен и отражает реальность. Однако в настоящее время большинство специалистов скорее склонны применять термин «дети с рекуррентными респираторными инфекциями» - РРИ, который и должен обозначать данную группу пациентов [4-6], хотя к этому определению хочется добавить слово «с частыми» (дети с частыми РРИ).

В качестве критерия для включения ребенка в данную группу можно использовать инфекционный индекс (ИИ), определяемый как отношение суммы всех случаев ОРИ в течение 1 года к возрасту ребенка. ИИ составляет в группе ЧБД от 1,1 до 3,5 , тогда как в группе редко болеющих он колеблется от 0,2 до 0,3 . Детей моложе 1 года относят к группе ЧБД, исходя из индекса резистентности (J), который определяется как отношение числа перенесенных ребенком острых заболеваний к числу месяцев наблюдения. В соответствии с этим, «часто болеющим» можно считать ребенка, J которого составляет $\geq 0,33$. Однако некоторые авторы (Романцов М.Г. и соавт., 2015) считают, что Ј в данной группе должен равняться 0,5 . Кроме того, для отнесения ребенка к группе ЧБД важен не столько сам факт определенного числа случаев заболевания, сколько их продолжительное и осложненное течение [7, 8].

По данным разных авторов, дети с частыми респираторными инфекциями составляют 14-18\% общей популяции детского населения, хотя некоторые называют более высокие цифры - до 40 и даже 50\%, что, вероятно, связано с неоднозначностью критериев оценки. Формирование этой группы детей зависит от возраста, эпидемиологических, экологических, социальноэкономических и ряда других факторов $[9,10]$.

Пик заболеваемости ОРИ отмечается у детей ясельных групп в дошкольных учреждениях, существенно ниже ее уровень - в школах, у учашихся младших классов.

Существуют две основные версии причин возникновения частых респираторных инфекций. Первая дисфункция иммунной системы, проявляющаяся при воздействии внешних факторов (неблагоприятная экологическая обстановка, высокая антропогенная нагрузка, социально-бытовое неблагополучие и т.п.). При этом важно отметить, что иммунные сдвиги у таких детей носят транзиторный характер, следовательно, их нельзя рассматривать как проявления иммунодефицита, и более правомерен термин «иммуносупрессия». Вторая причина - генетическая предрасположенность, которая также реализуется в результате воздействия перечисленных неблагоприятных внешних факторов. У ряда детей с частыми ОРИ высока вероятность наследственно обусловленного «позднего старта» иммунной системы, в пользу чего свидетельствует их семейный анамнез - указание на наличие высокой заболеваемо- сти респираторными инфекциями у одного или обоих родителей в детском возрасте, частота которой снижалась по мере их взросления.

Следует помнить, что частые повторные ОРИ характерны для детей с различными аллергическими заболеваниями. Это связано с особенностями их иммунного ответа, аллергическим отеком слизистых оболочек ВДП, снижением местного иммунитета на уровне слизистых оболочек, изменениями состава микробиоценоза кишечника и дыхательных путей, что типично для детей, предрасположенных к аллергии и имеющих аллергические заболевания. Поэтому в педиатрической практике основной контингент часто болеющих ОРИ составляют дети с аллергическими заболеваниями, в том числе - неустановленными, что, в частности, отмечает С.Г. Макарова [11].

Разные авторы указывают, что изменения в иммунном статусе отмечаются у 15-39\% детей с повторными респираторными инфекциями. Полученные в последние годы данные свидетельствуют о том, что иммунная система ЧБД, хоть и не имеет грубых первичных и приобретенных дефектов, характеризуется крайней напряженностью процессов иммунного реагирования, нарушением межклеточной кооперации и недостаточностью резервных возможностей, что, по-видимому, является результатом длительного и массивного антигенного воздействия на организм ребенка. Безусловно, такое состояние иммунной системы относится к факторам высокого риска развития осложнений - как местных (присоединение бактериального воспаления на разных уровнях дыхательного тракта), так и общих (формирование иммунокомплексной и иной иммунной патологии) [12-14].

Таким образом, у детей с РРИ отмечаются значительные изменения резистентности организма, что приводит к частым повторам заболевания, а частые заболевания, в свою очередь, способствуют угнетению различных звеньев иммунной системы. Образуется «порочный круг»: иммуносупрессия - частые инфекции - иммуносупрессия. Вторичная недостаточность иммунитета развивается под влиянием различных экзогенных воздействий на нормально функционирующую иммунную систему; одной из причин иммуносупрессии могут быть персистирующие герпесвирусные (обусловленные вирусами семейства Herpesviridae) инфекции [15-17].

Говоря о предупреждении повторных заболеваний, следует принимать во внимание и тот факт, что даже нетяжелая респираторная инфекция может стать причиной обострения какого-либо хронического процесса в случае наличия такового у ребенка $[4,5,8,9]$.

Важной составляющей нормального функционирования иммунной системы является состояние микробиоты слизистых, прежде всего - кишечника. Проблема нарушений микробиоценоза, определившаяся в последнюю треть XX столетия, но обозначенная еще 
И.И. Мечниковым, приобретает все большее значение в настоящее время. Можно с абсолютной уверенностью утверждать, что микроэкология человека является одним из определяющих факторов не только здоровья, но и качества его жизни. Сегодня возрастает давление не только на экологию окружающей среды, но и на микроэкологию человека. Организм отвечает на это давление комплексом общих патологических реакций, приводящих в конечном счете к супрессии иммунной системы с вытекающими отсюда последствиями в виде самых разнообразных заболеваний.

K числу наиболее распространенных синдромов, которые развиваются на фоне снижения иммунологической защиты, относится нарушение нормальной микробиоты - формирование дисбиоза. Эпидемиологические исследования последних лет свидетельствуют о чрезвычайной распространенности таких изменений среди населения, особенно детского. Дисбиоз достаточно часто обнаруживается у детей раннего возраста и может рассматриваться как фактор риска развития у них различных патологических состояний. Микробиоценоз, прежде всего кишечника, и иммунная система макроорганизма тесно взаимосвязаны. Основными механизмами противоинфекционной защиты, обусловленными микробиотой, являются колонизационная резистентность, антагонистические свойства нормального биоценоза по отношению к условнопатогенным микроорганизмам, а также универсальный иммуномодулирующий эффект. Известны и другие многообразные функции нормальной кишечной микрофлоры, а нарушение любой из функций микробиоценоза приводит к изменению различных видов метаболизма, в том числе - к возникновению дефицита микронутриентов: витаминов, микроэлементов, минеральных веществ, что в конечном счете также отрицательно действует на формирование иммунного ответа.

Нарушения состава и количественного соотношения в микробиоценозе кишечника имеют разнообразные причины. В частности, к экзогенным факторам, вызывающим такие нарушения, следует отнести антибиотикотерапию (нередко - необоснованно избыточную именно при частых респираторных инфекциях). Следует отметить, что основания для проведения антибактериальной терапии должны быть очень вескими, она не может носить характер упрощенной повседневной практики. В группе детей с частыми повторными респираторными инфекциями нарушения микробиоценоза той или иной степени выраженности встречаются практически у каждого ребенка. Нарушение микробиоценоза всегда влечет за собой снижение иммунного ответа и, наоборот, иммуносупрессия всегда сопровождается сдвигами микробиоты [18-21]. В связи с изложенным следует отметить, что при частых повторных респираторных инфекциях у детей обязательна коррекция микробиоценоза.
Важную роль в противостоянии вирусным инфекциям играют белки - интерфероны (ИФН). Семейство ИФН представлено тремя типами: ИФН 1-го, 2-го и 3-го типов. ИФН в организме продуцируются конституитивно и действуют как на выделившую их клетку, так и на клетки, расположенные поблизости. Основная причина постоянной выработки ИФН на физиологически значимом уровне обусловлена поддержанием готовности клеток противостоять вирусам. Практически нет клеток, не способных реагировать на действие ИФН 1-го типа. Следовательно, клеточная мембрана должна нести соответствующие рецепторы, а большинство клеток, за исключением эритроцитов и тромбоцитов, способны сами производить ИФН. После связывания с рецептором происходит образование транскрипционного комплекса ISGF3, состоящего из молекул транскрипции STAT1, STAT2, IRF9, активирующего пул генов, стимулируемых ИФН. Именно эти гены и определяют противовирусный, иммуномодулирующий и антипролиферативный эффекты данных белков. Для противовирусного воздействия достаточно пикомолярных концентраций ИФН 1-го типа и небольшого количества надлежащих рецепторов на клеточной поверхности. Иммуномодулирующий эффект достигается при значительно более высоких концентрациях лиганд, следовательно, для этого необходимо многократное увеличение числа взаимодействующих с ИФН рецепторов [22-24].

Не существует какой-либо разницы при воздействии на клетки организма экзогенных природных или рекомбинантных ИФН по сравнению с эндогенными, но именно концентрации лиганда и рецепторов определяют степень и силу производимого эффекта. Поэтому применение препаратов ИФН 1-го типа в пикомолярных концентрациях оправдано для противовирусного воздействия на слизистые при профилактике гриппа и ОРВИ, когда необходимо ускорить готовность клеток противостоять вирусной угрозе.

ИФН блокирует размножение всех видов человеческих респираторных вирусов, к нему отсутствует эффект привыкания, так как вирусы практически не способны приобрести устойчивость к его действию. ИФН характеризуется универсальностью, активностью против многих ДНК- и РНК-содержащих вирусов, поскольку он не взаимодействует с вирусами напрямую, а блокирует механизм их репликации. Кроме того, данный белок индуцирует выработку противовирусных антител, а также активирует моноциты и макрофаги [24-28].

Одним из наиболее доступных препаратов рекомбинантного ИФН является препарат для интраназального применения Гриппферон ${ }^{\circledR}$. Выраженное местное действие Гриппферона обусловлено тем, что в его основе лежит оригинальная комбинация ИФН- $\alpha 2 b$ человеческого рекомбинантного со специальными полимерными соединениями, составляющими водорастворимую вспомогательную часть препарата $[29,30]$. 
Введение в состав препарата полимерных соединений обеспечивает более продолжительный контакт ИФН со слизистой поверхностью носовой полости, что способствует более высокой степени защиты организма от вирусной инфекции.

Препарат Гриппферон ${ }^{\circledR}$ с целью профилактики и лечения ОРВИ успешно применяется в педиатрической практике уже много лет. Эффективна профилактическая схема применения Гриппферона у детей дважды в день (утром и вечером), по 2 капли в каждый носовой ход в течение 5-10 дней [31]. При использовании данной схемы показатели заболеваемости в основной группе снижались в 3,5-5,0 раз по сравнению с контрольной. Применение препарата приводило к увеличению содержания эндогенного ИФН, что доказано лабораторными исследованиями [31]. С профилактической целью Гриппферон ${ }^{\circledR}$ использовали как в межэпидемический период (в закрытых детских коллективах), так и в периоды выраженного эпидемического подъема. Установлены достоверные различия в уровнях заболеваемости детей, получавших Гриппферон ${ }^{\circledR}$, и детей контрольной группы. В основной группе респираторные вирусные инфекции практически не регистрировались [32].

Заслуживает внимания исследование О.М. Филькиной и соавт. [33]. Под наблюдением находились 160 детей в возрасте от 3 мес до 3 лет, отнесенных, по современной терминологии, к группе детей с РРИ. В основную группу были включены 100 детей, в группу сравнения -60 . Дети основной группы получали комплексную профилактику острых инфекционных заболеваний респираторного тракта с использованием назальных капель Гриппферон ${ }^{\circledR}$. Лечение проводилось с момента контакта ребенка с больным ОРВИ; дети получали препарат 2 раза в день в возрастной дозировке на протяжении 7 дней. Комбинированная профилактика включала также мероприятия по улучшению эмоционального статуса ребенка и повышению профилактической активности их родителей. Мероприятия проводились до контакта ребенка с больным ОРВИ и затем - на протяжении 3 мес после такого контакта. В группе сравнения комплексные мероприятия не включали назначение Гриппферона. В основной группе после контакта с заболевшим ОРВИ у $35 \%$ детей отмечался насморк, в ряде случаев - кашель и гиперемия слизистой ротоглотки. У $42 \%$ заболевших температура тела не превышала субфебрильных значений и держалась на протяжении лишь 1-2 дней. В группе сравнения не заболели только 1,9\% пациентов. К окончанию сроков наблюдения у детей основной группы существенно улучшился эмоциональный статус по сравнению с исходным $(\mathrm{p}<0,001)$ [33].

С учетом необходимости минимизации лекарственной нагрузки нами была предложена следующая схема реабилитации (иммунореабилитации) детей с РРИ, которую рекомендовано начинать использовать в конце августа - сентябре:
1. Сначала в целях профилактики повторных ОРИ у ЧБД назначают ИФН в виде назальных капель или спрея Гриппферон ${ }^{\circledR}$ по снижающейся схеме. Препарат последовательно вводят 4 раза в день в каждый носовой ход, затем - 3 раза в день, 2 раза в день и 1 раз на ночь (продолжительность каждого цикла - 5-10 дней), т.е. суммарный период использования препарата Гриппферон ${ }^{\circledR}$ может достигать 40 дней. Однако, как правило, в подавляющем большинстве случаев достаточно заметно меньшего промежутка времени, продолжительность которого зависит от динамики состояния ребенка и каждый раз определяется лечащим врачом. В случае возникновения респираторной инфекции осуществляется переход на лечебную схему использования Гриппферона с последующим возвращением к обозначенной профилактической.

2. Одновременно, если к началу реабилитации ребенок относительно здоров, у него нет очередного эпизода ОРИ, а температура тела находится в пределах нормы, подключаются системные или топические бактериальные лизаты согласно рекомендуемым схемам. При наличии клинических проявлений респираторной инфекции на момент начала реабилитационных мероприятий бактериальные лизаты назначают при нормализации температуры тела или снижении ее до субфебрильных значений.

3. Параллельно с мероприятиями по реабилитации проводят пролонгированную коррекцию микробиоценоза, которая включает короткий (10 дней) курс пробиотиков с последующим назначением пребиотиков (30-40 дней) с соответствующими диетическими рекомендациями. Указанные курсы повторяют с интервалом в 10-15 дней или без интервалов на протяжении всего холодного времени года. Целесообразен также прием качественных витаминно-минеральных комплексов [11].

Следует обратить особое внимание педиатров на крайне осторожный подход к назначению антибиотиков, которые нередко выписывают детям с частыми повторными респираторными заболеваниями из «лучших побуждений, направленных на предупреждение бактериальных осложнений». Как известно, антибиотикотерапия не только не предупреждает такие осложнения, но, напротив, способствует активации резистентной микрофлоры на фоне отсутствия конкуренции микроорганизмов, чувствительных к тому или иному препарату. Следует также учитывать, что, назначив системный антибиотик без должных оснований (к которым, в частности, относятся развитие бактериального осложнения или активация имеющегося хронического бактериального процесса), врач повышает риск возникновения побочных явлений, провоцирует нарушения микробиоценоза и способствует снижению иммунитета и распространению лекарственной резистентности.

В заключение следует отметить, что лекарственный препарат Гриппферон ${ }^{\circledR}$ (капли или спрей назальные) 
эффективен также для экстренной профилактики в тех случаях, когда существует реальная угроза заболевания ОРИ: при тесном контакте с больным или переохлаждении, особенно во время эпидемии. В данной ситуации однократный прием препарата в возрастной дозировке способен предупредить возникновение заболевания.

Таким образом, комплексные профилактические мероприятия с включением интраназального препарата рекомбинантного ИФН (Гриппферона) способствуют снижению числа ОРИ у детей, в том числе - в группе детей с частым повторением этих заболеваний, т.е. в группе ЧБД.

\section{Литература}

1. Баранов А.А., Цыбульская И.С., Альбицкий В.Ю. и др. Здоровье детей России (состояние проблемы) / М., 1999; 250 с.

2. Альбицкий В.Ю., Баранов А.А., Камаев И.А. Часто болеющие дети / Нижний Новгород, 2003; 174 с.

3. Современные подходы к лечению и реабилитации часто болеющих детей. Пособие для врачей. Под ред. Л.С. Балевой, Н.А. Коровиной, В.К. Таточенко / М.: Агентство медицинского маркетинга, 2006; 56 с.

4. Bellanti J. Recurrent respiratory tract infections in paediatric patients // Drugs. - 1997; 54 (Suppl. 1): 1-4.

5. Nafstad P., Hagen J., Oie L. et al. Day care centers and respiratory health // Pediatrics. - 1999; 103 (4 Pt. 1): 753-8.

6. Berdeaux G., Hervie C., Smajda C. et al. Parental quality of life and recurrent ENT infections in their children: development of a questionnaire // Rhinitis Survey Group. Qual-Life-Res. - 1998; 7 (6): 501-12.

7. Симованьян Э.Н., Денисенко В.Б., Григорян А.В. Часто болеющие дети: оптимизация программы лечения // Педиатрия. - 2007; 86 (4): 79-85.

8. Романцов М.Г., Мельникова И.Ю., Ершов Ф.И. Респираторные заболевания у часто болеющих детей / М., 2015; 159 с.

9. Заплатников А.Л. Клинико-патогенетическое обоснование иммунотерапии и иммунопрофилактики вирусных и бактериальных заболеваний у детей. Авторефр. дис. .... д-ра мед. наук. М., 2003; 48 с.

10. Самсыгина Г.А. Часто болеющие дети: проблемы патогенеза, диагностики и терапии // Педиатрия. - 2005; 1: 66-73.

11. Национальная программа по оптимизации обеспеченности витаминами и минеральными веществами детей России (и использованию витаминных и витаминно-минеральных комплексов и обогащенных продуктов в педиатрической практике) / М.: Педиатр, 2017; с. 78-82.

12. Титов Л.П., Кирильчик Е.Ю. Особенности иммунного статуса у часто и длительноболеющих детей с сопутствующей аллергической патологией // Иммунология. - 2000; 3: 29-33.

13. Намазова Л.С., Волков К.С., Торшхоева Р.М. и др. Новые возможности иммуномодулирующей терапии часто болеющих детей // Педиатрическая фармакология. - 2008; 5 (2): 12-20.

14. Захарова И.Н., Чебуркин А.В., Малиновская В.В. и др. Значение системы интерферонов в формировании иммунного ответа у детей с острыми респираторными вирусными инсекциями // Вопр. практ. педиатрии. - 2009; $4(6): 38-45$

15. Булгакова В.А., Балаболкин И.И., Сенцова Т.Б. Значение вирусной инфекции при аллергических болезнях у детей и подростков // Пульмонология детского возраста: проблемы и решения. - 2006; 6: 106-15.

16. Булгакова В.А., Балаболкин И.И., Ушакова В.В. Современное состояние проблемы часто болеющих детей // Педиатрич. фрармакол. - 2007; 4 (2): $48-52$
17. Краснов В.В., Позднякова М.А., Долгушева А.А. и др. Противогерпетический иммунитет, как составляющая здоровья воспитанников домов ребенка / Н. Новгород, 2012; 127 с.

18. Лобзин Ю.В. Макарова В.Г., Корвякова Е.Р. и др. Дисбактериоз кишечника / СПб, 2006; 256 с.

19. Костюкевич О.И. Современные представления о микробиоценозе кишечника. Дисбактериоз и его коррекция // Рос. мед. журн. - 2007; 15 (28): 2176-82.

20. Гордеец А.В., Пискунова С.Л., Черникова А.А. Оптимизация терапии ОРВИ у детей в период пандемии гриппа // Детские инфекции. - 2011; 4: 52-6.

21. Husebye $\mathrm{E}$. The pathogenesis of gastrointestinal bacterial overgrowth // Chemotherapy. - 2005; 51 (Suppl. 1): 1-22.

22. Pestka S., Krause C., Walter M. Interferons, interferon-like cytokines, and their receptors // Immunol. Rev. - 2004; 202: 8-32.

23. Gonzalez-Navajas J., Lee J., David M. et al. Immunomodulatory functions of type I interferons // Nat. Rev. Immunol. - 2012; 12: 125-35.

24. Schreiber $\mathrm{G}$. The molecular basis for differential type I interferon signaling // J. Biol. Chem. - 2017; 292 (18): 7285-94.

25. Черешнев В.А., Шмагель К.В. Иммунология / М.: Магистр-пресс, 2013; $448 \mathrm{c}$.

26. Tompkins W. Immunomodulation and Therapeutic Effects of the Oral Use of Interferon-alpha: Mechanism of Action // J. Interferon Cytokine Res. - 1999; 19 (8): $817-28$.

27. Levy D., Marié I., Durbin J. Induction and Function of Type I and III Interferon in Response to Viral Infection // Curr. Opin Virol. - 2011; 1 (6): 476-86.

28. Davidson S., Maini M., Wack A. Disease-Promoting Effects of Type I Interferons in Viral, Bacterial, and Coinfections // J. Interferon Cytokine Res. 2015; 35 (4): 252-64.

29. Попов В.Ф., Гапонюк П.Я., Варданян И.В. и др. Гриппферон - новое средство в лечении и профилактике гриппа. Тез. докл. «Современные технологии диагностики и терапии инфекционных болезней» / СПб, 1999; с. 241-2.

30.Гапонюк П.Я., Дорошенко Е.М. Роль российского препарата Гриппферон ${ }^{\circledR}$ в лечении и профилактике гриппа и других ОРВИ // Поликлиника. - 2008; 5: 22-6.

31. Шумилов В.И., Шевцов В.А., Лобов С.П. Грипп и ОРВИ: неспецифическая профилактика с использованием генно-инженерного $\alpha_{2}$-интерферона и его новых форм // Лечащий врач. - 2000; 9: 60-1.

32. Михайлова Н.А., Феклисова Л.В., Смирнова Т.А. и др. Повышение эффективности реабилитационного потенциала в период пребывания в санатории. Тез. докл. VIII Росс. нац. конгр. «Человек и лекарство». М., 2001; с. 248

33. Филькина О.М., Пыхтина Л.А., Кочерова О.Ю. и др. Комбинированная медико-психологическая профилактика острых респираторных вирусных инфекций у часто болеющих детей с применением топических интерферонов // Эфффективн. фрармакотер. Педиатрия. - 2015; 2: 10-4.

\section{OPTIMIZING THE MANAGEMENT OF CHILDREN WITH RECURRENT RESPIRATORY INFECTIONS DURING SEASONAL DISEASE OUTBREAKS}

Professor V. Krasnov, Dr. Med. Sci.

Privolzhsky Research Medical University

Acute respiratory infections are a very common pathology in childhood. The vast majority of respiratory infections are of viral origin. Another problem concerns children with frequent recurrent respiratory tract diseases, which are more prevalent in allergic patients and often accompanied by bacterial complications and chronic disease exacerbations. Complex prevention of recurrent respiratory infections should include microbiocenosis correction, vitamins and minerals intake as well as the use of intranasal interferon-based medications.

Key words: pediatrics, children, acute respiratory viral infections, recurrent respiratory infections, prevention, interferon, Grippferon.

For citation: Krasnov V. Optimizing the management of children with recurrent respiratory infections during seasonal disease outbreaks // Vrach. - 2018; 29 (8): 3-7. https://doi.org/10.29296/25877305-2018-08-01 